\title{
(t)
}

\section{COMPORTAMENTO ÉTICO E CRÍTICA AO PRECONCEITO BURGUÊS}

\section{ETHICAL BEHAVIOR AND CRITICISM TO THE BOUGEOIS PREJUDICE}

\section{Ranieri Carli'}

\section{RESUMO}

Este artigo procura delinear os componentes mais elementares de uma ética marxista, para então focar na lacuna que há entre o preconceito, que se atém àquilo que existe de particular e imediato no homem, e o comportamento de natureza essencialmente ética, que se eleva à generalidade. A intenção é demonstrar como o preconceito limita-se ao chão raso do cotidiano, ao passo que, no polo oposto, a ética supera-o, purificando o homem singular rumo à universalidade genérica. Enfim, tomaremos alguns expoentes do pensamento conservador que fundaram as suas respectivas filosofias em preconceitos tipicamente burgueses.

Palavras-chave: Cotidiano. Ética. Preconceito. Pensamento burguês.

\section{ABSTRACT}

This article seeks to outline the most basic components of a Marxist ethics, and then focus on the gap that exists between the prejudice, which clings to what exists in particular and immediate in man, and the behavior of essentially ethical nature, which rises to universality. The intent is to demonstrate how prejudice is limited to the superficial ground of everyday life, while at the opposite pole ethics overcomes it, purifying the natural man towards generic universality. Finally, we will take some exponents of conservative thought that founded their respective philosophies in typically bourgeois prejudices.

Keywords: Daily life. Ethics. Prejudice. Bourgeois thought.

Submetido em 05/02/2014

Aceito em 20/06/2014

1 Doutor em Serviço Social; professor da Escola de Serviço Social da Universidade Federal Fluminense no campus de Rio das Ostras. E-mail: raniericarli@yahoo.com.br. 


\section{temporalis}

\section{INTRODUÇÃO}

Para chegarmos ao núcleo do nosso problema, partiremos de uma ontologia da vida cotidiana; assim teremos à mão as categorias necessárias para se pensar a ética. A noção a ser brevemente defendida é a de que a ética se apresenta como a mediação particular entre o singular e o universal.

Assim posto, partindo da vida cotidiana, as condições para a crítica dos preconceitos também estarão dadas. Ilustraremos as nossas ideias lançando luz sobre teorias, as mais diversas, que generalizaram os preconceitos típicos de uma sociedade de capitalismo maduro; serão objeto de crítica algumas das teses respaldadas em preconceitos burgueses nos alvores do período imperialista do capital, como as de Gobineau, Lombroso e Moebius, por exemplo; o leitor observará que são ideologias que se edificam sobre preconceitos da burguesia imperialista.

Ao cabo do artigo, retornaremos ao cotidiano com o propósito de superarmos os preconceitos, cuja possibilidade está dada depois da suspensão ética e, assim, o retorno ao cotidiano com o sujeito ético mais educado, humanizado, realçado em seu núcleo universal.

\section{COMPORTAMENTO ÉTICO E PRECONCEITO}

Uma autêntica crítica dos preconceitos deve partir necessariamente de uma ontologia da vida cotidiana, pois, como veremos, o preconceito, ele mesmo, é um elemento estruturalmente vinculado à cotidianidade, atendo-se a ela de forma inextricável, sem superá-la em absolutamente qualquer medida.

A primeira aproximação a uma ontologia da vida cotidiana requer caracterizá-la como um reino da heterogeneidade.

A vida cotidiana é aquela vida dos mesmos gestos, rito e ritmos de todos os dias: é levantar nas horas certas, dar conta das atividades caseiras, ir para o trabalho, para a escola, para a igreja, cuidar das crianças, fazer o café da manhã, fumar um cigarro, almoçar, jantar, tomar cerveja, a pinga ou o vinho, ver televisão, praticar um esporte de sempre, ler jornal, sair para um "papo" de sempre etc. Nessas atividades, é mais o gesto mecânico e automatizado 
que as dirige do que a consciência (CARVALHO, 1996, p. 23).

A vida rotineira dos homens é um reino da heterogeneidade porque, submersos nela, os homens têm todos os seus sentidos tomados ao mesmo tempo, em um só fluxo. Uma vez que o cotidiano não constitui um meio homogêneo a avocar concentradamente quaisquer desses sentidos, nenhum deles se satisfaz plenamente. Todos os sons, as imagens, as proporções, os objetos à nossa mão, as mais variadas e multiformes relações que demandam a atenção instantânea etc. perfazem a prática dos homens tomados pelo curso ininterrupto do cotidiano.

A síntese de Lukács (1982, v. 1, p. 65) a esse respeito é clara: "o homem que está comprometido nela [na vida cotidiana] é sempre o homem inteiro". Daí a noção de que o cotidiano é a objetivação desse homem inteiro.

Lefebvre está correto ao alocar as ruas como o lugar cotidiano por excelência em sociedades modernas. É uma constatação similar à de Lukács, quando o filósofo húngaro diz que o homem cotidiano é o homem inteiro e, portanto, heterogêneo. Ainda que o filósofo francês esteja mais preocupado com a crítica ao cotidiano historicamente burguês, Lefebvre caminha no mesmo sentido de Lukács ao limitar especialmente o amplo espaço da rua como o âmbito no qual se dá o fluxo heterogêneo desse homem inteiro:

A rua passageira, ativa, sem outra relação com a natureza senão o céu e as nuvens, ou algumas árvores e flores, a rua representa a cotidianidade em nossa vida social [...]. Lugar de passagem, de interferências, de circulação e de comunicação, a rua torna-se por uma inversão surpreendente o reflexo das coisas que ela condensa, tornando-se mais viva que as coisas. A rua torna-se o microcosmo da vida moderna. O que se esconde, ela arrasta para longe da obscuridade. Ela o faz público [...] a rua conduz ao público o que se passa em algum lugar, em segredo. Ela o deforma, mas o insere no texto social (LEFEBVRE, 1955, v. 2, p. 310). 


\section{temporalis}

Nas ruas, dão-se os encontros mais diversos, plenos de particularidades, sendo lugar de passagem, de interferências, de circulação e de comunicação, como explicou Lefebvre; aqui está a representação máxima da cotidianidade na sociedade burguesa contemporânea. No curso sem cessar da rua, o público está em contato de modo imediato. No curso exaustivo das ruas modernas, são homens inteiros em contato com homens inteiros, diriam Lukács e Lefebvre em uníssono. Certamente, há cotidiano por entre as paredes do nosso quarto; porém, Lefebvre chama a atenção para o espaço privilegiado da rua no cotidiano de sociedades de capitalismo avançado, dado o seu fluxo continuado de sensações, algo impossível de se experimentar com a mesma intensidade em âmbito doméstico.

Ao determinar a vida cotidiana como um reino da heterogeneidade, Lukács não pretende diminuí-la em face de modalidades da práxis humana em que o ser social se realiza inteiramente (como a ética). É a intenção do filósofo marxista apenas especificar a peculiaridade do cotidiano, abstraindo suas leis imanentes, compondo o quadro geral do seu ser-precisamente-assim. A posição inversa encontra-se em Heidegger (1997, v. 2, p. 86), por exemplo, para quem o "falatório" do cotidiano implica a "decadência" do homem, a "alienação" do seu ser, que se manteria purificado caso permanecesse isolado do fluxo múltiplo que movimenta a sua rotina. Típico representante das ideologias do período imperialista do capital, em Heidegger consta a apologia ao singular isolado, recluso em seu quarto, sem contato com o público das ruas, colocando-se dessa maneira no polo diametralmente inverso ao de Lukács (CARLI, 2013).

A vida cotidiana é mais do que a simples sequência de tarefas rotineiras em torno das quais o singular se envolve; é a esfera na qual se realizam tanto a dimensão genérica quanto a dimensão singular do ser social. Ao reproduzir as suas próprias condições de subsistência, cada indivíduo singular reproduz indiretamente as condições que garantem a subsistência de sua generalidade. Daí o trabalho ser tanto o labor cotidiano, cujo fim último é a subsistência do singular, como a atividade genérica do homem em interação com a natureza (HELLER, 2002). Embora a prática cotidiana seja a realização do singular e do universal em um mesmo ato, 
os interesses que movem o homem cotidiano são os aspectos mais imediatos de sua vida: é pouco provável que um homem se alimente projetando conscientemente que, assim, contribui com sua cota parte para a subsistência do gênero humano; os homens se alimentam diariamente para saciar sua própria fome e não a fome genérica, embora a fome de cada um seja sempre e efetivamente uma manifestação particular da fome genérica. De tudo, resta a singularidade como categoria central da vida cotidiana.

Determinar que a vida genérica e a vida singular não são oposições dicotômicas é o passo inicial para se considerar a ética, para a teoria social de Marx. Com efeito, como Marx (2004, p. 107, grifos do autor), ele mesmo, esclarece nos Manuscritos econômico-filosóficos, "a vida individual e a vida genérica do homem não são diversas".

Por qual razão a ética está referida na recusa de Marx em separar em instâncias dicotômicas o gênero e o singular? Pois a ética está em valorizar a dimensão genérica da vida nos instantes em que a vida cotidiana nos coloca alternativas a serem tomadas; suspendem-se a moralidade cotidiana e os interesses direcionados ao singular, típicos da cotidianidade, para, então, se realizar o valor ético. O fluxo ininterrupto da cotidianidade é interrompido temporariamente no momento de reflexão ética: diante de uma determinada alternativa posta pela vida cotidiana, um homem concreto pode se defrontar com uma questão de fundo ético. A decisão pode encaminhar-se para valorizar ou a dimensão particular ou a dimensão universal da vida; há a possibilidade de que a decisão seja a de isolar-se do mundo público à maneira de Heidegger, ou posicionar-se a favor dos processos históricos que varrem as ruas à maneira de Lefebvre; as alternativas são postas pelo tempo e lugar vivenciados por homens concretos em situações concretas, com todas as mediações possíveis. Quando a opção que tende ao universal é a decisão escolhida, realiza-se a ética na prática.

Falando sobre a estética, Lukács chamou a atenção para a transformação operada no homem que se eleva eticamente à generalidade. De homem inteiro no cotidiano para homem inteiramente em posições de caráter ético, o "homem inteiramente" 


\section{temporalis}

não se orienta para os interesses mais superficiais da sua existência (LUKÁCS, 1982, v. 1, p. 79).

A consciência genérica movimenta o homem que se fez inteiramente na sua práxis. Elevar-se à consciência genérica é condição sem a qual a ética permaneceria irrealizável. Para além de seus aspectos mais prosaicos, cotidianos, singulares, esse processo se traduz em alçar-se na prática ao pertencimento a uma universalidade.

Elevar-se à consciência genérica nas posições de sua prática é uma noção que está implicada na seguinte passagem de Marx (2002, p. 74-75):

O homem se vê, se reconhece primeiro em seu semelhante, a não ser que já venha ao mundo com um espelho na mão ou como um filósofo fichtiano para quem basta o "eu sou eu". Através da relação com o homem Paulo, na condição de seu semelhante, toma o homem Pedro consciência de si mesmo como homem. Passa, então, a considerar Paulo com pele, cabelos, em sua materialidade paulina - a forma em que se manifesta o gênero homem.

Na materialidade do outro, o homem pode se reconhecer enquanto uma universalidade. Daí deriva a consciência genérica necessária ao comportamento ético: reconhecer-se como gênero ao ver no outro a sua própria humanidade; é apenas na relação concreta com Paulo que Pedro se conscientiza do seu pertencimento a uma universalidade. Pedro está apto a comportar-se eticamente com relação a Paulo no preciso instante em que reconhece que a sua humanidade também está contida neste último.

Percebam que Marx parte de uma ontologia da vida cotidiana para falar em consciência de gênero: a materialidade imediata do outro comporta a humanidade, sua pele, cabelos etc. A despeito das particularidades que se expressam em diferenças de pele, de cabelos etc., o outro pertence à mesma universalidade. Diversos em seus aspectos prosaicos, Pedro e Paulo compõem uma mesma e única generalidade. O universo humano não é um todo indiscriminado e uniforme; ao contrário, é uma unidade de diversos. A consciência genérica está impossibilitada quando se perde o caráter unitário em meio às diversidades; quando se 
esconde a universalidade em meio às particularidades cotidianas; quando as diferenças de pele ou de cabelo impedem Pedro de reconhecer o humano na materialidade de Paulo.

Qualquer um, neste exato instante, pode contemplar a rua, o espaço cotidiano por excelência, e verificar imediatamente as particularidades dos indivíduos singulares que lá transitam: distinções de classe, sexo, idade, etnia etc.; são distinções que particularizam o pertencimento dos indivíduos singulares à universalidade do gênero humano. O comportamento ético está precisamente em não perder de vista que o pertencimento ao gênero humano não se exclui graças a essas particularidades. Ao revés, o preconceito se fixa em tais particularidades, naturalizando-as, para lhes atribuir um maior ou menor grau de humanidade. Grupos de indivíduos deteriam mais humanidade que outros, que seriam considerados subumanos, proto-humanos etc. Um homem, proprietário, adulto, branco, seria mais humano do que aqueles que, no plano do cotidiano, não carregassem pelas ruas esses aspectos peculiares. Chegaria a essa conclusão uma pessoa que portasse os preconceitos típicos de uma sociedade de capitalismo tardio.

O preconceito nasce do cotidiano, muito embora seja verificável também em outras esferas da vida social, como as ciências humanas, por exemplo. Agnes Heller (2000, p. 43) estabelece essa correlação com maestria:

O preconceito é a categoria do pensamento e do comportamento cotidianos. Os preconceitos sempre desempenharam uma função importante também em esferas que, por sua universalidade, encontram-se acima da cotidianidade; mas não procedem essencialmente dessas esferas, nem aumentam sua eficácia; ao contrário, não só a diminuem como obstaculizam o aproveitamento das possibilidades que elas comportam. Quem não se liberta de seus preconceitos artísticos, científicos e políticos acaba fracassando, inclusive pessoalmente.

O preconceito procede essencialmente da vida cotidiana; a sua presença nas ciências humanas implica que elas foram buscá-lo no solo cotidiano, generalizando-o sob a forma de uma tese sociológica, filosófica, antropológica etc. As ciências humanas 


\section{temporalis}

são capazes de arrancar o preconceito das raízes cotidianas e tratá-lo de modo afirmativo, generalizado como condição da natureza humana. Diz Heller, na citação acima, que esse procedimento implica obstáculo para as possibilidades comportadas nas ciências do homem.

Existem ilusões historicamente legítimas que não podem ser equalizadas ao mero preconceito. Os revolucionários franceses guiaram a sua práxis com a convicção de que realizariam o reino da razão; Condorcet e outros iluministas escreveram cada linha de sua obra convictos dessa ideia. "Mas, dado que a burguesia não podia dar aquele passo de importância histórico-universal e que inaugurou seu domínio a não ser sobre a base de uma ultrageneralização intelectual e emocional, aquela ideologia não era um sistema de preconceitos" (HELLER, 2000, p. 52-53); que o reino da razão não tenha se concretizado não implica que os iluministas baseavam-se em preconceitos; as ilusões historicamente legítimas da revolução burguesa não se fundavam em um sistema de preconceitos porque tendiam à realização genérica do ser social e não se atinham às particularidades costumeiras da vida ordinária dos homens.

\section{A CRÍTICA AO PRECONCEITO BURGUÊS: GOBINEAU, LOMBROSO E MOEBIUS}

Situação diversa é a de Gobineau. Em sua obra, o preconceito transformou-se em instrumento ideológico de luta a favor da ordem do capital, em ideia que adquire o estatuto de potência prática, como ocorre com toda e qualquer ideologia. Nas vésperas do período imperialista do capital, em 1855, o filósofo francês publica o seu Ensaio sobre a desigualdade das raças. Aqui há um exemplo claro e manifesto da transposição do preconceito cotidiano para o âmbito das ciências do homem. Eis uma ilustração inicial:

A variação relativa à melanina faz do homem o mais simples e encontra-se na parte inferior da escala do ser humano. O caráter de animalidade estampada em sua pélvis lhe impôs o seu destino desde o instante de sua concepção. Ele nunca sairá do círculo intelectual mais restrito. Não é, portanto, um fato bruto, puro e simples que o negro possua a fronte 
estreita e recuada, que traga na parte média de seu crânio os indícios de certas energias grosseiramente potentes. Se as suas faculdades intelectuais são pobres ou mesmo nulas, ele possui no desejo e, consequentemente, na vontade uma intensidade muitas vezes terrível. Vários de seus sentidos são desenvolvidos com vigor desconhecido para as outras duas raças: o gosto e o cheiro, principalmente (GOBINEAU, 1967, p. 195-196).

Sem meias palavras, o filósofo francês mistifica as particularidades físicas, que, segundo ele, são características de certas raças, para lhes imputar um determinado comportamento. Indivíduos singulares, que detêm tais aspectos, estariam fadados "desde o instante de sua concepção" a jamais saírem do "círculo intelectual mais estreito"; a natureza os teria criado assim, segundo a argumentação do filósofo.

De fato, as ultrageneralizações de Gobineau, frutos de preconceitos hipertrofiados em teses filosóficas, determinam inclusive o gosto e o cheiro das raças. A ausência de paladar é projetada por Gobineau (1967, p. 196) aos negros, pois acredita que "todos os alimentos Ihes são bons, nenhum o desagrada, nenhum Ihes causa repulsa. O que querem é comer, comer em excesso, furiosamente. Não há carniça indigna de se aglutinar em seu estômago, por mais repugnante que seja".

No que tange aos brancos, é preferível que Gobineau (1967, p. 197) fale por si mesmo:

De energia refletida, ou por melhor dizer, uma inteligência enérgica; o sentido do útil, mas dando um significado a esta palavra bastante largo, mais elevado, mais corajoso, mas ideal que as nações amarelas; uma perseverança que dá conta dos obstáculos e encontra sempre os meios de superá-los; com uma grande potência física, um instinto extraordinário de ordem, não mais apenas como garantia de descanso e de paz, mas como meio indispensável de conservação, e, ao mesmo tempo, um gosto pronunciado da liberdade, mesmo extrema; uma hostilidade declarada contra esta organização formalista em que dormem de bom grado os chineses, como 


\section{temporolis}

também contra o despotismo arrogante, o único a colocar freio suficiente nos povos negros.

Daí provém a recusa de Gobineau (1967, p. 198) em aceitar a miscigenação, uma vez que, a seus olhos, a mistura das raças redundaria inevitavelmente em degeneração. O "estado ideal", para o filósofo, é aquele em que as três raças "permanecem estritamente separadas", o que resultaria "sem dúvida alguma na supremacia das mais belas tribos brancas", sendo que as "variedades amarelas e negras se arrastariam eternamente aos pés das nações dessa raça". Seria um "estado ideal" que a "história não presenciou".

Gobineau (1967, p. 312) conclui que, entre os brancos, os mais típicos são os arianos, especialmente os do norte da Europa, "onde a raça ariana melhor conserva e renova sua pureza".

As teses de Gobineau significam um aburguesamento da teoria racista, que nasce originariamente com as reações da aristocracia contra a revolução francesa (LUKÁCS, 1972). Tais teses não tiveram repercussão de imediato, senão nas décadas seguintes ao lançamento do Ensaio sobre a desigualdade das raças, no momento em que o capital aportava em seu período imperialista e a teoria racista de Gobineau passou a cumprir uma necessidade ideológica relevante: a de demonstrar no plano do conhecimento que a fundação de impérios por parte dos europeus estava teoricamente justificada em face de sua superioridade racial; a colonização imperialista seria uma consequência natural e até mesmo resultante da ascendência dos brancos sobre as outras raças.

Cesare Lombroso seguiu rente a Gobineau quando escreveu O homem branco e o homem de cor, em 1871, embora o italiano exacerbe as ultrageneralizações do francês e divida a humanidade em apenas duas raças: os brancos e os de cor (negra, amarela ou qualquer outra). Ainda assim, para finalizar as suas conclusões são semelhantes a do filósofo francês: "somente nós os brancos alcançamos a mais perfeita simetria nas formas do corpo" (LOMBROSO, 2012, p. 122). É sugestivo que Lombroso fale na primeira pessoa do plural; sente o orgulho de ser membro da espécie cujos aspectos fazem com que seja fisicamente superior às demais. Para esses ideólogos do capital imperialista, sejam 
duas ou três raças a compor o gênero humano, é sempre inevitavelmente a branca a raça senhorial.

Soma-se a isso o fato de que Lombroso fala em nome do homem burguês imperialista também quando o assunto é a situação da mulher. Sendo um criminalista, Lombroso intenta registrar os caracteres físicos das chamadas delinquentes, com especial atenção às prostitutas (consideradas por ele como criminosas, é óbvio). Então, na obra de Lombroso, denominada A mulher delinquente, a prostituta e a mulher normal, há uma ampla descrição do físico das mulheres pertencentes às três categorias expressas no título do livro:

[No texto de Lombroso] Dos genitais femininos até os olhos assassinos tudo será identificado e relacionado: a mulher assassina terá seus órgãos facilmente detectados assim como seu rosto patibular. As caixas cranianas das prostitutas diferem das ossaturas das mulheres consideradas normais. Assim como os criminosos natos, existem as prostitutas natas. E a mulher é potencialmente mentirosa, é atavicamente mentirosa. A mulher é mais delinquente que o homem e também mais cruel (TÓRTIMA, 2002, p. 210).

Além dos títulos já citados, a obra de Lombroso constitui-se ainda de $\mathrm{O}$ homem delinquente, cujo propósito é diferenciar fisicamente os autores de crimes dos homens "normais"; O homem genial, que também investiga os traços físicos peculiares às chamadas genialidades, o que inclui ser necessariamente branco; 0 antissemitismo e as ciências modernas, livro no qual Lombroso se coloca desfavorável à perseguição política aos judeus, pois, graças às suas formas corpóreas e morais, não se pode imputar apenas a eles o delito político; entre outros textos.

Seguidor de Lombroso e Gobineau, o neurologista alemão Paul Julius Moebius foi o autor de A inferioridade mental da mulher, publicada em 1900. Basta o título do panfleto para que compreendamos o seu caráter conservador à maneira de Lombroso, ideologicamente respaldado em preconceitos da burguesia imperialista. 


\section{temporalis}

Vejamos: em um momento do seu texto, ao versar sobre a pertinência do uso do termo "estupidez" para balizar as diferenças entre os sexos, Moebius (1982, p. 33-34) chega à seguinte conclusão:

É indubitável que as faculdades mentais do homem e da mulher são muito diferentes entre si; porém, será possível um paralelo [com a estupidez] graças ao fato de que as mulheres possuírem maior capacidade para umas coisas e os homens para outras, ou bem, as mulheres são verdadeiramente deficientes com respeito aos homens?

Um antigo provérbio dá a resposta: "cabelos longos, cérebro curto".

Para conferir uma certidão de cientificidade a seus argumentos, Moebius recorre precisamente a Lombroso e seu escrito já mencionado A mulher delinquente, a prostituta e a mulher normal. Baseando-se em tal exposição e, logo, tendo a fisiologia dos crânios como ponto de partida, Moebius (1982, p. 35) afirma que "a mulher está alocada entre a criança e o homem" em vários níveis, inclusive o psíquico.

Sendo uma verdadeira e pobre síntese entre os já vulgares Lombroso e Gobineau, Moebius (1982, p. 38) defende que, quando se trata de capacidades intelectivas, as mulheres estariam em pé de igualdade com os "homens pouco desenvolvidos", que, para ele e também para seu mentor Gobineau, seriam os negros:

Nos homens pouco desenvolvidos na parte mental (um negro, por exemplo), encontram-se os mesmos dados anatômicos listados no lóbulo parietal da mulher, enquanto que nos homens mais bem dotados fisicamente, o grande desenvolvimento do lóbulo temporal Ihes dá um aspecto completamente distinto.

Fisicamente, então, a mulher estaria condicionada a desenvolver uma vida psíquica inferior aos homens. É esse o argumento principal de Moebius. Dono de um positivismo tosco, o neurologista imputa ao "instinto" um lugar de destaque entre os comportamentos biologicamente condicionados da mulher; enquanto a mulher se moveria por instintos, o homem, pela inteligência 
razoável; a primeira é instintiva e o segundo, "lucidamente consciente", conforme as palavras do neurologista (MOEBIUS, 1982, p. 40-41).

Mas não se enganem. As palavras de Moebius (1982, p. 42-43) podem manifestar com maior energia o desprezo de um burguês conservador: "muitas das características femininas são reconhecidas por sua semelhança com a besta; antes de tudo, a ausência de opinião própria. O que geralmente é considerado bom e verdadeiro, é para as mulheres bom e verdadeiro". Para ele, formam todos um mesmo conjunto, apenas com diferenças de grau entre si: bestas, negros, mulheres etc. Ademais, "como os animais, produzem o mesmo desde tempos imemoriais, e assim o ser humano estaria estacionado em um estado originário se não existissem mais que mulheres. Cada progresso é obra de um homem". Deriva daí, entre outras coisas, que, sob a interpretação de Moebius (1982, p. 49), a mulher não está apta a se tornar "mestre". Quando Moebius (1982, p. 51) se depara com uma mulher com certo talento, como nas artes plásticas, por exemplo, o neurologista não se dá por vencido e assevera se tratar de um "hermafroditismo psíquico".

Enfim, a inferioridade mental da mulher seria uma obra da natureza, que determinou biologicamente que à mulher se destinasse o cuidado com os filhos: "a Natureza exige da mulher amor e abnegação maternais" (MOEBIUS, 1982, p. 57, grifos do autor). Fazer com que a mulher almeje novos horizontes serviria apenas para lhe deixar "inquieta e transtornar suas obrigações maternais" (MOEBIUS, 1982, p. 58). É de se notar como as ideologias das classes dominantes atribuem seus preconceitos à obra da natureza; isso lhes facilita a tarefa de eternizar as contradições que nascem da divisão burguesa do trabalho; assim, a sociedade burguesa lava as mãos quanto às contradições de sua forma de sociabilidade, responsabilizando a natureza por elas. Torna-se desnecessário superar a sociedade burguesa, uma vez que as contradições que poderíamos lhe arrogar são, na verdade, motivadas pela fisiologia de certas pessoas, como o tamanho do crânio das mulheres. Com a chancela de ser o porta-voz da natureza, Moebius (1982, p. 74-75) declara como vã qualquer luta a favor da emancipação da mulher, haja vista que "a Natureza deu 


\section{temporalis}

preferência ao homem e demonstrou querer formar nele o tipo mais perfeito".

Ao adotarem o ponto de vista dos senhores do poder, tanto Lombroso quanto Moebius reproduzem os chavões em torno da condição feminina na sociedade capitalista: condicionamento biológico ao cuidado com as gerações vindouras, comportamento instintivo e ausência de reflexão racional, caráter naturalmente subalterno em face do poder masculino, docilidade e resignação etc. É preciso discernir com atenção que os preconceitos do par formado por Lombroso e Moebius falam de um tempo determinado: o período em que a família burguesa não somente gira em torno do homem branco proprietário, mas também de um homem que constitui impérios, pois, no tempo vivido por Lombroso e Moebius, que se acrescente à propriedade burguesa desse homem a qualidade de ser imperialista. É, assim, um tempo diverso daquele presenciado em Aristóteles, quando a família monogâmica do escravismo se consolidava.

\section{CONCLUSÃO}

Em A destruição da razão, Lukács (1972, p. 542) diz algo sobre Gobineau que vale para Lombroso e Moebius: "o ponto de partida e tendência fundamental de Gobineau é a luta contra a democracia, contra a ideia 'contrária à ciência' e 'antinatural' da igualdade dos homens". A igualdade burguesa, jurídico-formal entre os homens é rechaçada por Gobineau e os demais justamente porque os homens não seriam naturalmente iguais. Moebius chega mesmo a alegar que as leis deveriam tratar as mulheres de forma diferenciada: seres inferiores não deveriam ser alvo da mesma legislação que os superiores; daí a sua ideia, por exemplo, de que, em um tribunal, as mulheres não devam merecer "excessivo valor" quando forem testemunhas e, quando forem réus, que não sejam muito exigidas, graças à sua inclinação natural à mentira, às "falsas manifestações" (MOEBIUS, 1982, p. 66).

Nas teses dos autores burgueses estudados acima, a universalidade do gênero humano é fracionada segundo as demandas do capital imperialista. O particular é tratado como o universal; quando falam em homem, querem dizer o homem branco, 
um homem rotulado, adjetivado, particularizado, longe de ser o homem universal sem adjetivações a que se refere Marx. Parafraseando Marx, em Gobineau e companhia, poderíamos afirmar que, sendo branco, Pedro não se reconhece humano em Paulo porque esse último é negro. Paulo não seria a manifestação da generalidade a que pertence Pedro, que não se identifica com a materialidade paulina, com sua pele, cabelos etc. Não sendo uma relação entre membros diversos de uma mesma unidade, Pedro se sentiria superior a Paulo, considerando-o um subumano, passível de ser colonizado, de ser objeto de exploração imperialista, de ser até mesmo extinto. Enfim, Pedro estaria impossibilitado de ser ético.

O preconceito é um dos obstáculos para a realização do comportamento ético em toda sua completude. Vimos que a ética implica a suspensão do particular cotidiano, em direção à universalidade do gênero humano. Ater-se ao particular é negar o comportamento ético. Há objetivações do ser social que são potencialmente portadoras da universalidade (trabalho, ciência, arte, política, moral, educação etc.). Por meio delas, o singular cotidiano pode alçar-se à generalidade, do modo explicado por Netto (1996, p. 70, grifos do autor):

As suspensões que engendram estas objetivações, contudo, não cortam com a cotidianidade (insuprimível e ineliminável) - são, justamente, "suspensões da cotidianidade". Elas - que permitem aos indivíduos, via homogeneização, assumirem-se como seres humano-genéricos - não podem ser contínuas: estabelecem um circuito de retorno à cotidianidade: ao efetuar este retorno, o indivíduo enquanto tal comporta-se cotidianidade com mais eficácia e, ao mesmo tempo, percebe a cotidianidade diferencialmente: pode concebê-la como espaço compulsório de humanização (de enriquecimento e ampliação do ser social). Está contida aqui, nitidamente, uma dialética de tensões: o retorno à cotidianidade após uma suspensão (seja criativa, seja fruidora) supõe a alternativa de um indivíduo mais refinado, educado (justamente porque se alçou à consciência humano-genérica). 


\section{temporalis}

O retorno ao cotidiano, após a suspensão momentânea necessária ao comportamento ético, supõe a possibilidade de que o sujeito ético esteja mais "refinado, educado", segundo as palavras de Netto. O indivíduo singular se vê ressalvado em seu núcleo humano. Portador da consciência genérica, agora, esse sujeito tende a ser mais humanizado, refinado no seu trato cotidiano; percebe as particularidades cotidianas de forma diferenciada, possivelmente como espaço de "enriquecimento e ampliação do ser social”. Para ele, a universalidade do gênero humano não está por trás das particularidades cotidianas dos demais indivíduos de seu convívio (peles, cabelos etc.), senão é necessariamente composta por essas últimas. Assim, as multiplicidades cotidianas, as diversidades com as quais se defronta nas ruas, significam para o sujeito ético o rico e múltiplo universo humano de que somos parte.

\section{REFERÊNCIAS}

CARLI, Ranieri. Fenomenologia e questão social: limites de uma filosofia. Campinas: Papel Social, 2013.

CARVALHO, Maria do Carmo Brant. O conhecimento da vida cotidiana: base necessária à prática social. In: CARVALHO, Maria do Carmo Brant; NETTO, José Paulo. Cotidiano: conhecimento e crítica. São Paulo: Cortez, 1996. p. 13-63.

GOBINEAU, Arthur. Essai sur l'inégalité des races humaines. Paris: Pierre Belfond, 1967.

HEIDEGGER, Martin. Ser e tempo. Petrópolis: Vozes, 1997. 2 v.

HELLER, Agnes. Sobre os preconceitos. In: HELLER, Agnes. 0 cotidiano e a história. Rio de Janeiro: Paz e Terra, 2000. p. 43-63.

2002.

. Sociología de la vida cotidiana. Barcelona: Península,

LEFEBVRE, Henri. Critique de la vie quotidienne. Paris: Arche, 1955. $2 \mathrm{~V}$. 
LOMBROSO, Cesare. L'uomo bianco e l'uomo di colore: letture sull'origine e la varietà delle razze umane. Bologna: Archetipo Libri, 2012.

LUKÁCS, György. El asalto a la razón: la trayectoria del irracionalismo desde Schelling hasta Hitler. Barcelona; México: Grijalbo, 1972.

- Estética I: la peculiaridad de lo estético. Barcelona; México: Grijalbo, 1982. 4 v.

MARX, Karl. O capital: crítica da economia política. Rio de Janeiro: Civilização Brasileira, 2002. v. 1.

. Manuscritos econômico-filosóficos. São Paulo: Cortez,

2004 .

MOEBIUS, Paul Julius. La inferioridad mental de la mujer: la dificiencia mental fisiológica de la mujer. Barcelona: Bruguera, 1982.

NETTO, José Paulo. Para a crítica da vida cotidiana. In: CARVALHO, Maria do Carmo Brant; NETTO, José Paulo. Cotidiano: conhecimento e crítica. São Paulo: Cortez, 1996. p. 64-93.

TÓRTIMA, Pedro. Crime e castigo para além do Equador. Belo Horizonte: Inédita, 2002. 